\title{
Short term Outcome of Coronary Artery Bypass Surgery in Patients with Impaired Left Ventricular Systolic Function

\author{
Elhusseiny Gamil ${ }^{1}$ MD, Zakaria Al-mashtoly ${ }^{1}$ MD, Abdelgawad El Khonizy ${ }^{1}$ MD, Medhat Refaie ${ }^{1}$ MD,
} Abdallah Mahmoud ${ }^{1}$ MSc
}

\section{*Corresponding Author: Abdallah Sami Mahmoud doctor15186@gmail.com}

\section{Received for publication} January 30, 2020; Accepted February 02, 2020; Published on line February 16, 2020.

\section{Copyright 2020 The Authors} published by Al-Azhar University, Faculty of Medicine, Cairo, Egypt. All rights reserved. This an openaccess article distributed under the legal terms, where it is share the work provided it is properly cited. The work cannot be changed in anyway or used commercially.

doi:10.21608/aimj.2020.23234. 1121

${ }^{1}$ Department of Cardiothoracic Surgery, Faculty of Medicine, Al-Azhar University, Cairo, Egypt permissible to download and

\begin{abstract}
Abstrat
Background: Coronary artery bypass graft surgery (CABG) in patients with left ventricular dysfunction was associated with improved survival compared to medical treatment and coronary stenting. However, the risk of surgery is still high. We aimed to evaluate the short-term outcome of CABG in patients with an ejection fraction of $\leq 40 \%$.

Patient and Methods: Forty patients with ejection fraction (EF) $\leq 40 \%$ underwent CABG between December 2015 and August 2019. Patients with moderate to severe mitral regurgitation, concomitant severe liver and kidney impairment, re-operative $\mathrm{CABG}$, who had concomitant procedures with $\mathrm{CABG}$ were excluded. The mean age was $56.72 \pm 12.44$ years; 30 patients $(75 \%)$ were males. Twenty-six patients $(65 \%)$ were diabetics, 28 patients $(70 \%)$ were hypertensive, 18 patients $(45 \%)$ were dyslipidemic, 22 patients (55\%) were smokers, and 4 patients (10\%) were obese. The preoperative ejection fraction ranged from $20 \%$ to $40 \%$, with a mean of $34.62 \%$

Results: The mean cardiopulmonary bypass time was 90.8 minutes, and ischemic time was 49.8 minutes. Seventeen patients (42.5\%) needed inotropic support intraoperatively, and 16 patients (40\%) needed an intraaortic balloon. Five patients $(12.5 \%)$ had postoperative ischemia, one patient $(2.5 \%)$ had re-exploration for bleeding, and one patient $(2.5 \%)$ had acute renal failure. The mean ICU stay was $70.5 \pm 45.63$ hours, hospital stay was $8.9 \pm 4$ days, and three patients $(7.5 \%)$ had operative mortality. After 6 months operatively, the ejection fraction improved to reach a mean value of $39.87 \pm 5.02 \%$ compared to the preoperative ejection fraction of $32.8 \pm 8.8 \%$. $(\mathrm{p}<0.001)$
\end{abstract}

Conclusion: Coronary artery bypass grafting can be performed safely in patients with depressed left ventricular function with low short-term morbidity and mortality. CABG could lead to the improvement in the ejection fraction in patients with evidence of viable myocardium.

Key words: Coronary artery bypass grafting; Left Ventricular Systolic Function; low ejection fraction.

associated with a better quality of life compared to medical therapy and percutaneous coronary intervention. ${ }^{4}$

The effectiveness of CABG in patients with low ejection fraction has been confirmed in numerous controlled trials, especially if symptoms of angina or ischemia are present. ${ }^{5,6}$ The purpose of this study was to evaluate the short-term results after coronary artery bypass grafting $(\mathrm{CABG})$ in patients with left ventricular ejection fraction less than or equal to $40 \%$ in our institution.

\section{PATIENTS AND METHODS}

The outcome of coronary artery bypass grafting ventricular (LV) function. Despite the improvement in surgical technique, myocardial protection, and postoperative care, the surgical risk of $\mathrm{CABG}$ remains high in patients with depressed left ventricular function. ${ }^{1}$

Despite the increased mortality after $\mathrm{CABG}$ in patients with decreased left ventricular function, $\mathrm{CABG}$ remains the recommended revascularization strategy in those patients, in addition to the diabetics and patients with multi-vessel disease. ${ }^{2,3}$ CABG was

a substantial contributions to the article

\section{INTRODUCTION}


patients to measure the cardiac chambers, the ejection fraction, regional wall motion abnormalities, hypokinesia, dyskinesia, akinesia, and evaluation of other valves. Coronary angiography was performed for all patients, and the number of diseased vessels and site of lesions were reported.

All patients received their morning dose of cardiac medications. Intramuscular $10 \mathrm{mg}$ morphine sulfate before transfer to the operating theatre was given to all patients. Monitoring started preoperatively using five leads ECG, direct arterial blood pressure, and pulse oximetry.

General anesthesia was used in all patients. A median sternotomy was performed, and the internal thoracic artery was harvested. The Aorto-caval cannulation was then performed, and an aortic root cannula was inserted for cardioplegia administration, venting, and de-airing. Cold intermittent blood cardioplegia was used, the dose was repeated every 25 minutes until the end of distal anastomoses. A (7-0) polypropylene suture was used for distal targets. After completing the last distal anastomoses, the aortic root vent was used to de-air the heart, and the cross-clamp was then removed.

After completion of all anastomoses and establishing a stable intrinsic or paced cardiac rhythm, the patient was weaned from cardiopulmonary bypass. In some instances, mechanical circulatory support in the form of an intra-aortic balloon counterpulsation was needed, according to the hemodynamic profile of the patient. Thoracostomy drainage tubes were carefully placed, usually, in any opened pleural space and the mediastinum, pacing wires were then inserted, and the chest and leg were then closed in layers. We reported the aortic cross-clamp cardiopulmonary bypass time and the number of grafts.

All patients were evaluated thoroughly during their intensive care unit stay, during their hospital stay and after 6 months post-operative. We reported the duration of mechanical ventilation and the length of ICU and hospital stay. Operative complications, including stroke, end-organ dysfunction, and infectious complications, were recorded.

\section{Statistical analysis:}

The data were collected, coded, revised, verified, and computerized. Statistical analyses were done using SPSS statistical package version 16. (IBM Corp, Chicago, IL, USA) Qualitative data were presented in the form of numbers and percentages, and quantitative variables as mean, standard deviation (SD) and range. A paired t-test was used to compare the change in the echocardiographic data at 6 months. A P-value of less than 0.05 was considered significant.

\section{RESULTS}

The age of our patients ranged from 41 to 74 years, with a mean of $56.72 \pm 12.44$ years. Thirty patients $(75 \%)$ were males, and 10 patients $(25 \%)$ were females. Preoperative data are presented in table 1. Eighteen patients had the New York Heart Association (NYHA) class of IV (45\%), 19 patients had class III to IV (47.5\%), and 3 patients were in NYHA functional class II to III (7.5\%).

\begin{tabular}{|c|c|}
\hline & $n=40$ \\
\hline Age (years) & $56.72 \pm 12.44$ \\
\hline Males & $30(75 \%)$ \\
\hline Diabetes mellitus & $26(65 \%)$ \\
\hline Hypertension & $28(70 \%)$ \\
\hline Dyslipidemia & $18(45 \%)$ \\
\hline Smokers & $22(55 \%)$ \\
\hline $\begin{array}{l}\text { Obesity (Body mass index > } \\
\text { 30) }\end{array}$ & $4(10 \%)$ \\
\hline Ejection fraction (\%) & $32.8 \pm 8.8$ \\
\hline $\begin{array}{l}\text { Left ventricular end-systolic } \\
\text { diameter }(\mathrm{mm})\end{array}$ & $6.12 \pm 0.52$ \\
\hline $\begin{array}{l}\text { Left ventricular end-diastolic } \\
\text { diameter }(\mathrm{mm})\end{array}$ & $6.7 \pm 0.39$ \\
\hline
\end{tabular}

Table 1: Preoperative patients' data. (Continuous data are presented as mean and standard deviation and categorical data as number and percent).

Preoperative ECG revealed that 24 patients exhibited anterolateral ischemia $(60 \%), 8$ patients had anteroseptal ischemia (20\%), and 8 patients $(20 \%)$ had anteroseptal and inferior ischemia.

The left ventricular ejection fraction (EF) ranged from $20 \%$ to $40 \%$, with a mean of $34.62 \%$. Echocardiographic data are shown in table 1.

One patient had a single-vessel disease (2.5\%), 6 patients had a two-vessel disease $(15 \%) 17$ patients suffered from three-vessel disease (42.5\%), 4 patients had five-vessel disease (10\%), and 12 patients had four-vessel disease (30\%). Angiographic mapping is shown in table 2.

Cardiopulmonary bypass time ranged from 60 to 130 minutes, with a mean of 90.8 minutes, and ischemic time ranged from 25 to 70 minutes, with a mean of 49.8 minutes.

Seventeen patients $(42.5 \%)$ received three grafts, 12 patients $(30 \%)$ had four grafts, 6 patients $(15 \%)$ had two grafts, 4 patients were found in need for five grafts, and one patient had a single graft.

Seventeen patients $(42.5 \%)$ needed inotropic support intraoperatively, and 16 patients (40\%) needed intra-aortic balloon (IABP).

The left internal mammary artery (LIMA) was grafted to the left anterior descending artery (LAD) in 38 patients $(95 \%)$, and the saphenous vein was 
used in 36 patients (90\%) either to LAD or other targets.

\begin{tabular}{|c|c|c|}
\hline & Lesion & n $(\%)$ \\
\hline \multirow[t]{3}{*}{ Left main } & Normal & $\begin{array}{l}31 \\
(77.5 \%)\end{array}$ \\
\hline & Critical lesion & $\begin{array}{l}7 \\
(17.5 \%)\end{array}$ \\
\hline & $60 \%$ lesion & $2(5 \%)$ \\
\hline \multirow[t]{3}{*}{$\begin{array}{ll}\text { Left } & \text { anterior } \\
\text { descending } & \end{array}$} & Normal & $\begin{array}{l}7 \\
(17.5 \%)\end{array}$ \\
\hline & Subtotal & $\begin{array}{l}25 \\
(62.5 \%)\end{array}$ \\
\hline & $\begin{array}{l}\text { Totally } \\
\text { occluded }\end{array}$ & $8(20 \%)$ \\
\hline \multirow[t]{2}{*}{ Diagonals } & Normal & $\begin{array}{l}22 \\
(55 \%)\end{array}$ \\
\hline & $\begin{array}{l}\text { Significant } \\
\text { lesion }\end{array}$ & $\begin{array}{l}18 \\
(45 \%)\end{array}$ \\
\hline \multirow[t]{3}{*}{ Ramus intermedius } & Normal & $6(15 \%)$ \\
\hline & $90 \%$ lesion & $2(5 \%)$ \\
\hline & $\begin{array}{l}\text { Sub totally } \\
\text { occluded }\end{array}$ & $2(5 \%)$ \\
\hline \multirow[t]{6}{*}{ Circumflex } & Normal & $\begin{array}{l}22 \\
(55 \%)\end{array}$ \\
\hline & $70 \%$ lesion & $2(5 \%)$ \\
\hline & $80 \%$ lesion & $4(10 \%)$ \\
\hline & $90 \%$ lesion & $\begin{array}{l}5 \\
(12.5 \%)\end{array}$ \\
\hline & $\begin{array}{l}\text { Sub totally } \\
\text { occluded }\end{array}$ & $4(10 \%)$ \\
\hline & $\begin{array}{l}\text { Totally } \\
\text { occluded }\end{array}$ & $3(7.5 \%)$ \\
\hline \multirow[t]{3}{*}{ Right coronary } & Normal & $\begin{array}{l}10 \\
(25 \%)\end{array}$ \\
\hline & $85 \%$ lesion & $2(5 \%)$ \\
\hline & $\begin{array}{l}\text { Totally } \\
\text { occluded }\end{array}$ & $\begin{array}{l}24 \\
(60 \%)\end{array}$ \\
\hline \multirow[t]{2}{*}{$\begin{array}{l}\text { Posterior descending } \\
\text { artery }\end{array}$} & Normal & $\begin{array}{l}36 \\
(90 \%)\end{array}$ \\
\hline & $\begin{array}{l}\text { Significant } \\
\text { lesion }\end{array}$ & $4(10 \% 0$ \\
\hline
\end{tabular}

Table 2: Preoperative angiographic mapping. (Data are presented as number and percent)

Postoperative ischemia was encountered in 5 patients $(12.5 \%)$, two of them (5\%) had lateral wall ischemia, and three (7.5\%) suffered from anterolateral wall ischemia.

Re-exploration for bleeding was needed in one patient (2.5\%), and two patients $(5 \%)$ had atrial fibrillation. One patient $(2.5 \%)$ had sternal wound infection, and two patients (5\%) had sternal dehiscence. One patient $(2.5 \%)$ had acute renal failure requiring dialysis. The mean ICU stay was $70.5 \pm 45.63$ hours, and hospital stay was $8.9 \pm 4$ days. Three patients $(7.5 \%)$ had operative mortality.

At six months follow up, 4 patients (10\%) had lateral wall ischemia, and $2(5 \%)$ had an anterior myocardial infarction. Ejection fraction ranged from $21 \%$ to $49 \%$, and the mean was $38.6 \%$. Follow-up echocardiographic data are presented in table 3.

\begin{tabular}{l|lll} 
& Preoperative & At 6 months & $\mathrm{p}$ \\
\hline EF (\%) & $32.8 \pm 8.8$ & $39.87 \pm 5.02$ & $<0.001$ \\
$\begin{array}{l}\text { LVEDD } \\
(\mathrm{mm})\end{array}$ & $6.7 \pm 0.39$ & $6.69 \pm 0.06$ & 0.66 \\
$\begin{array}{l}\text { LVESD } \\
(\mathrm{mm})\end{array}$ & $6.12 \pm 0.52$ & $6.22 \pm 0.43$ & 0.041 \\
\hline
\end{tabular}

Table 3: Comparison of the preoperative and 6 months postoperative echocardiographic data. (Data are presented as mean and standard deviation) (EF: ejection fraction; LVEDD: left ventricular enddiastolic diameter; LVESD: Left ventricular endsystolic diameter).

\section{DISCUSSION}

The outcome of CABG in patients with low ejection fraction is the subject of ongoing researches. Currently, CABG is the recommend revascularization methods in patients with depressed ventricular function. ${ }^{2,3}$ We performed a study to describe patients who underwent CABG with low ejection and report our institutional experience and outcome.

Obesity is a risk factor for coronary artery disease, and in our study, four patients $(10 \%)$ were obese, which is consistent with other series. ${ }^{7}$ Obesity increased the risk of operative complications and associated with poor long-term outcomes. ${ }^{5-7}$ We had a high prevalence of diabetes in our study, which is higher than other reports. ${ }^{7}$ Diabetes is strongly associated with coronary artery disease, and longterm outcome of diabetic patients with ischemic heart disease is more favorable when patients have CABG compared to PCI.

Our results showed an increase in EF following CABG; however, there was no evident improvement in cardiac dimensions. The improvement in the $\mathrm{EF}$ is consistent with several reports that showed significant improvement in $\mathrm{EF}$ following $\mathrm{CABG}$ in low EF patients. Samady and coworkers 
demonstrated that $65 \%$ of low $\mathrm{EF}(\leq 30 \%)$ patients had a significant increase in LVEF. ${ }^{8}$ Bouchart and associates reported a significant increase in $\mathrm{EF}$ from $22.2 \%$ to $33.5 \%$ after $\mathrm{CABG}^{7}$, and Carr and colleagues assessed the $\mathrm{EF}$ at different time points after surgery starting from 1 month to 11 years and recorded a significant improvement in the $\mathrm{EF}$ at all the time points. ${ }^{9}$ The improvement in $\mathrm{EF}$ was reported in several other reports, and this could be attributed to the revascularization of viable myocardium. ${ }^{10}$

The variation in the percentage of increase in $\mathrm{EF}$ following $\mathrm{CABG}$ may be due to variable mixed areas of scar tissue (fibrosis) and viable myocardium. Therefore, the myocardium showed a different level of improvement in cardiac function after revascularization. ${ }^{8}$

Many authors suggested the theory of a positive association between the amount of viable myocardium before CABG and the possibility of improvement in $\mathrm{LV}$ function after $\mathrm{CABG} .{ }^{11}$ Moreover, Elsasser and colleagues showed that the level of recovery of $\mathrm{LV}$ function post $\mathrm{CABG}$ is inversely proportional to the extent of fibrosis confirmed by histological examination of the biopsies taken from the hibernating myocardium during $\mathrm{CABG} .{ }^{12}$

De Rose and coworkers showed that both the degree and timing of recovery in regional LV function depends on the extent of transmural myocardial fibrosis. Patients having small amounts of viable myocardium showed a significant delay (6-month) in regional LV function improvement after CABG, in comparison to patients who have more quantities of viable myocardium. ${ }^{13}$

Among the 40 coronary bypass procedures we performed, there were 3 total surgical site infections for an overall incidence of $7.5 \%$, one patient had superficial wound infection $(2.5 \%)$, and the other two patients $(5 \%)$ had sternal dehiscence. Our results are consistent with other series, which indicate no increase in sternal complication risk in patients with low ejection fraction. ${ }^{14}$

\section{REFERENCES}

1. Lam S, Donal E, Kraigher-Krainer E, et al. Epidemiology and clinical course of heart failure with preserved ejection fraction. Eur J Heart Fail. 2011; 13: 18-28.

2. Alkhouli M, Alqahtani F, Alreshidan M, et al. Incidence, Predictors, and Outcomes of Early Acute Myocardial Infarction Following Coronary Artery Bypass Grafting, 00029149/@ 2019 Elsevier Inc.

3. Karabdic H, Hasanovic A, Kabil A, et al. Improvement of Ejection Fraction After Coronary Artery Bypass Grafting Surgery in
Ridderstolpe and coworkers found that 109 (2.6\%) patients developed sternal wound infection following isolated $\mathrm{CABG}$ prior to discharge from the hospital. Deep sternal wound infections occurred in $28(0.7 \%)$ patients, while $81(1.9 \%)$ patients have a superficial sternal wound infection. ${ }^{15}$

In this study, there was one patient $(2.5 \%)$ who developed renal impairment. In a review of over $51000 \mathrm{CABG}$ procedures performed by Bridgewater and associated from 1999 to 2002, the incidence of acute renal failure was constant over the four years, ranging from 4 to $5 \%$. In a 2006 data analysis report from the STS by Santos and coworkers, the incidence of acute renal failure was $3.6 \%$ after isolated $\mathrm{CABG}$, and 7.5 and $12.9 \%$ after $\mathrm{CABG}$ combined with aortic or mitral valve replacement, respectively.

In summary, this study showed that the risk of CABG in patients with low ejection fraction is acceptable compared to the published series and the common standards. Patients with low ejection fraction may benefit from revascularization with an improvement of the ejection fraction during followup.

The major limitation of the study was the number of patients included and the lack of a comparison group. Additionally, this is a single-center study, and generalization of the results may be an issue. A larger comparative study is recommended.

\section{CONCLUSION}

Coronary artery bypass grafting can be performed safely in patients with depressed left ventricular function with low short-term morbidity and mortality. CABG could lead to the late improvement in the ejection fraction in patients with evidence of viable myocardium.

Patients with Impaired Left Ventricular Function. Med Arh. 2014; 68(5): 332-334.

4. Borlaug A and Paulus J. Heart failure with preserved ejection fraction: pathophysiology, diagnosis, and treatment. Eur Heart J. 2011; 32: 670-679.

5. Detre M, Lombardero S, Brooks M, et al. The effect of previous coronary artery bypass surgery on the prognosis of patients with diabetes who have acute myocardial infarction: Bypass Angioplasty Revascularization Investigation investigators. N Engl J Med. 2000; 342: 989-997. 
6. Kunadian V, Zaman A, Qiu W. Revascularization among patients with severe left ventricular dysfunction: a meta-analysis of observational studies. Eur J Heart Fail. 2011; 13: 773-784.

7. Bouchart F, Tabley A, Litzler Y, et al. Myocardial revascularization in patients with severe ischemic left ventricular dysfunction. Long term follow-up in 141 patients. Eur J Cardiothorac Surg. 2001;20:1157-1162.

8. Samady H, Elefteriades A, Abbott BG, et al. Failure to Improve Left Ventricular Function After Coronary Revascularization for Ischemic Cardiomyopathy Is Not Associated With Worse Outcome.Circulation. 1999; 100:12981304.

9. Carr A, Haithcock E, Paone G, et al. Longterm outcome after coronary artery bypass grafting in patients with severe left ventricular dysfunction. Ann Thorac Surg. 2002;74: 15311536.

10. Elefteriades A, Morales L, Gradel C, et al. Results of coronary artery bypass grafting by a single surgeon in patients with left ventricular ejection fractions $<$ or $=30 \%$. Am J Cardiol. 1997;79:1573-1578.

11. Bax J, Visser C, Poldermans D, et al. Relationship between preoperative viability and postoperative improvement in LVEF and heart failure symptoms. J Nucl Med. 2001;42:79-86.

12. Elsasser A, Schlepper M, Wolf-Peter K, et al. Hibernating myocardium, an incomplete adaptation to ischemia Circulation. 1997;96:2920 -2931.

13. De Rose J, Toumpoulis K, Balaram K. Preoperative prediction of long term survival after coronary artery bypass grafting in patients with low left ventricular ejection fraction. J Thorac Surg. 2005; 129: 314-321.

14. Borger A, Rao V, Weisel D, et al. Deep sternal wound infection: risk factors and outcomes. Ann Thorac Surg 1998: 65(4): 1050-1056.

15. Ridderstolpe L, Gill H, Granfeldt $\mathrm{H}$, et al.Superficial, and deep sternal wound complications: incidence, risk factors, and mortality. 2001: 20:68-75. 